\title{
When adults suffer from the children's diseases
}

A 32-year-old man patient was referred to the urgency department for cutaneous lesions with perioral and palmar involvement. Four days before, the patient has started with fever and odynophagia. The patient also revealed the existence of recent contact with a child diagnosed with Hand, Foot and Mouth disease.

On physical exam, he presented vesico-papular lesions with erythematous base in palms (Figure 1) and slight mucous discharge in cavum with few erythematous lesions (Figure 2). On reevaluation, two days later, the rash was found to have reached the plantar surface (Figure 3). Analytically only with slight elevation of inflammatory parameters. Conservative treatment was instituted, associated with transmission prevention measures. The patient has recovered fully within two weeks of the onset of symptoms.

Hand, Foot and Mouth disease is a self-limiting viral infection caused by Enterovirus, which Coxsackie A16 and Enterovirus 71 are the most common serotypes ${ }^{1,2,3}$. The disease usually occurs in children under 5 years of age and in immunocompromised adults ${ }^{1,4}$. It is rare in immunocompetent adults, infecting $11 \%$ of the exposed adults and only $1 \%$ of them exhibit some clinical manifestation?2.

The virus is transmitted by the oral/fecal-oral route and is more prevalent in developing countries ${ }^{1}$. The diagnosis is clinical, so laboratory confirmation is not usually required ${ }^{4}$.

The major challenges include differential diagnosis (herpes simplex, herpangina, chickenpox, erythema multiforme, aphthous stomatitis) and potential complications, especially of Enterovirus 71 (myocarditis, encephalitis, aseptic meningitis and pulmonary edema) $)^{1,3,4}$.

The treatment is symptomatic and the disease resolves in 7-10 days, usually without complications ${ }^{1}$.

\section{REFERENCES}

1. Omaña-Cepeda C, Martínez-Valverde A, Sabater-Recolons M, Jané-Salas E, Marí-Roig A, López-López J. A literature review and case report of hand, foot and mouth disease in an immunocompetent adult. BMC Res Notes. 2016; 9:165.

2. Downing $C$, et al. Coxsackievirus $A 6$ associated hand, foot and mouth disease in adults: Clinical presentation and review of the literature. J Clin Virol. 2014; 62:122.

3. Kaminska K, Martinetti G, Lucchini R, Kaya G, Mainetti C. Coxsakievirus A6 and Hand, Foot and Mouth Disease: Three Case Reports of Familial Child-to-Immunocompetent Adult Transmission and a Literature Review. Case Rep Dermatol. 2013; 5:203-209.

4. Murase C, Akiyama M. Hand, Foot and Mouth Disease in an Adult. N Engl J Med. 2018; 378:e20.

\section{DIAGNOSIS}

\section{Hand, Foot and Mouth disease}

\author{
Ângela Mota, João Tavares \\ Centro Hospitalar Tondela-Viseu, E.P.E. Portugal
}

Figure 1. Vesico-papular lesions on palms.

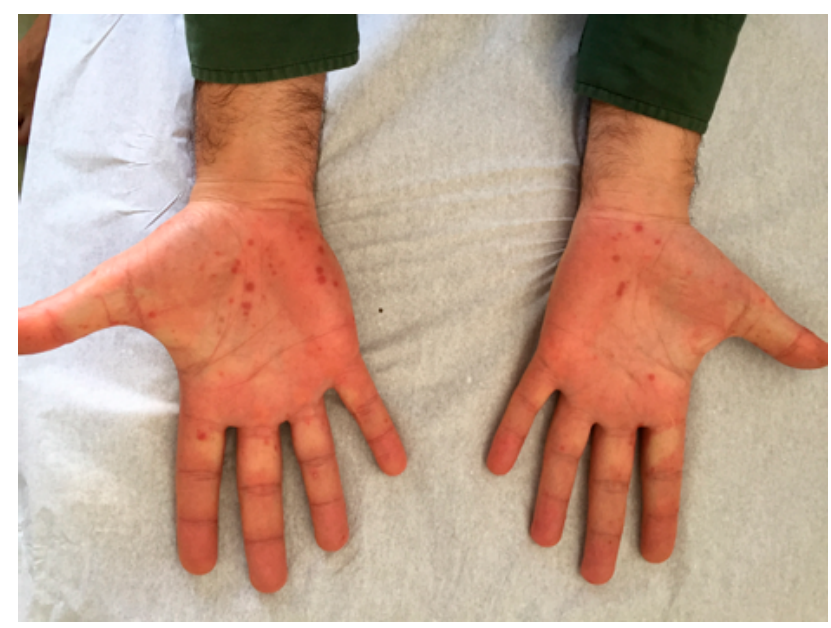

Figure 2. Oral erythematous and perioral vesicular lesions.

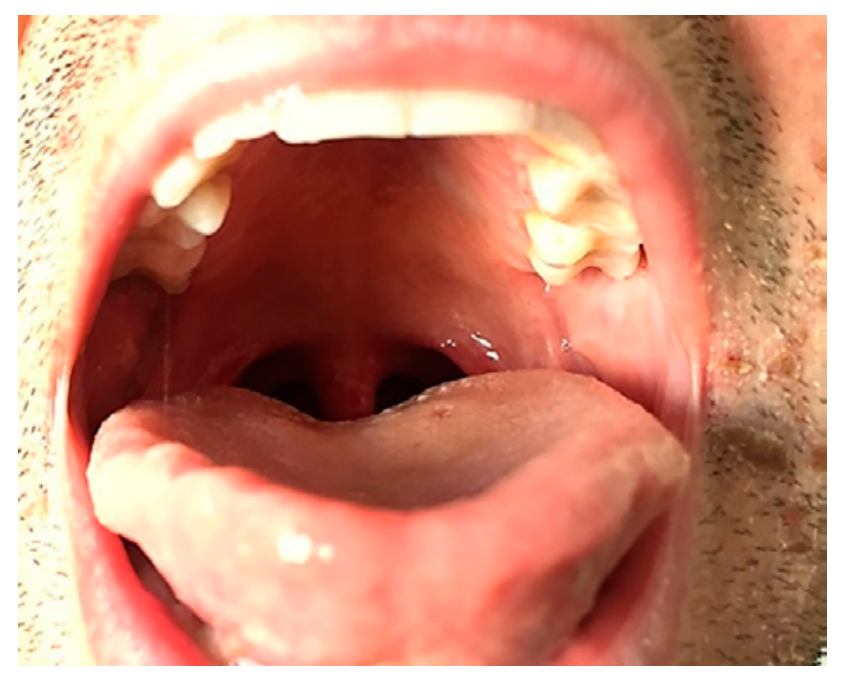

Figure 3. Vesico-papular lesions in plants.

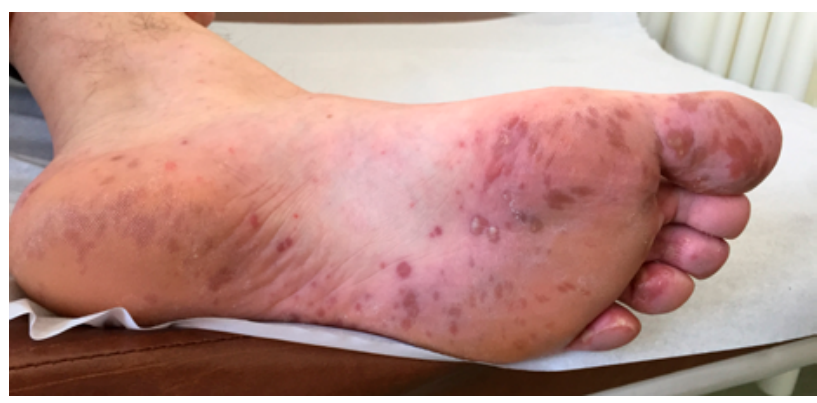

Correspondencia: angelamota1987@gmail.com

Cómo citar este artículo: Mota Â, Tavares J

When adults suffer from the children's diseases. Galicia Clin 2020; 81 (2):60

Recibido: 20/01/2019; Aceptado: 30/01/2019 // http://doi.org/10.22546/56/1890 